\title{
Targeting Programmed Cell Death to Improve Stem Cell Therapy: Implications for Treating Diabetes and Diabetes-Related Diseases
}

OPEN ACCESS

Edited by:

Sudjit Luanpitpong,

Mahidol University, Thailand

Reviewed by:

Sina NASERIAN,

Hôpital Paul Brousse, France

*Correspondence: Kun Xiong

xiongkun2001@163.com Wei-tao Yan

beakeyywt@126.com

Specialty section:

This article was submitted to

Stem Cell Research,

a section of the journal

Frontiers in Cell and Developmental

Biology

Received: 05 November 2021 Accepted: 06 December 2021 Published: 16 December 2021

Citation:

Zhang $Q$, Wan X-x, Hu X-m, Zhao W-j,

Ban $X-x$, Huang $Y-x$, Yan $W-t$ and Xiong $K$ (2021) Targeting Programmed

Cell Death to Improve Stem Cell

Therapy: Implications for Treating

Diabetes and Diabetes-

Related Diseases.

Front. Cell Dev. Biol. 9:809656.

doi: 10.3389/fcell.2021.809656

\section{Qi Zhang ${ }^{1}$, Xin-xing Wan ${ }^{2}$, Xi-min $\mathrm{Hu}^{1}{ }^{1}$, Wen-juan Zhao ${ }^{1}$, Xiao-xia Ban ${ }^{1}$, Yan-xia Huang ${ }^{1}$, Wei-tao Yan $^{1 *}$ and Kun Xiong ${ }^{1 *}$}

${ }^{1}$ Department of Anatomy and Neurobiology, School of Basic Medical Sciences, Central South University, Changsha, China,

${ }^{2}$ Department of Endocrinology, Third Xiangya Hospital, Central South University, Changsha, China

Stem cell therapies have shown promising therapeutic effects in restoring damaged tissue and promoting functional repair in a wide range of human diseases. Generations of insulinproducing cells and pancreatic progenitors from stem cells are potential therapeutic methods for treating diabetes and diabetes-related diseases. However, accumulated evidence has demonstrated that multiple types of programmed cell death (PCD) existed in stem cells post-transplantation and compromise their therapeutic efficiency, including apoptosis, autophagy, necroptosis, pyroptosis, and ferroptosis. Understanding the molecular mechanisms in PCD during stem cell transplantation and targeting cell death signaling pathways are vital to successful stem cell therapies. In this review, we highlight the research advances in PCD mechanisms that guide the development of multiple strategies to prevent the loss of stem cells and discuss promising implications for improving stem cell therapy in diabetes and diabetes-related diseases.

Keywords: programmed cell death, stem cell, apoptosis, pyroptosis, necroptosis, diabetes

\section{INTRODUCTION}

Stem cells (SCs) are unique cell populations distinguished by the capacity of self-renewal and differentiation (Biswas and Hutchins, 2007; McElhinney et al., 2020). These unique features of SCs make them the preferred candidate for tissue repairing (Yang et al., 2019; Yang et al., 2020; Qin et al., 2021). According to different developmental stages, SCs can be categorized into distinct types, such as embryonic SCs (ESCs), induced pluripotent SCs (IPSCs), and adult SCs (ASCs) (Bogliotti et al., 2018; Hu et al., 2021). These SCs are widely utilized for regenerative medicine therapies (Gurusamy et al., 2018; Fatima et al., 2019).

The worldwide shortage of pancreas donors remains a major hurdle to islet transplantation, and SC therapy represents a highly promising alternative approach for treatments of advanced diabetes (Saleem et al., 2019; Chen et al., 2020). In SC therapy for type 1 diabetes mellitus (T1DM), insulin-producing cells can be generated from SCs (Manzar et al., 2017; Chen et al., 2020). Neural SCs (NSCs), bone marrow-derived mesenchymal SCs (BM-MSCs), and umbilical cord MSCs (UC-MSCs) are a promising treatment for diabetic retinopathy and foot ulcers (Zhang et al., 2017; Zhao et al., 2020a; Huang Q. et al., 2021).

However, the cell death of SC post-transplantation creates significant challenges to transplantation therapy (Mastri et al., 2014). According to different death processes, cell 
death are categorized as: programmed cell death (PCD), a precise and genetically controlled cellular death, and nonPCD, also called necrosis (Cheng et al., 2018; Guo LM. et al., 2020; Bedoui et al., 2020). Extensive pharmacological and genetic strategies have been developed to inhibit PCD to prevent cell loss and thus improve physiological function of organs (Wang Z. et al., 2018; Yuan et al., 2019; Wu X. et al., 2020; Yan W.-T. et al., 2021). Increasing evidence indicates a close link between PCDs and cell death of transplanted SCs (Ho et al., 2017; Wang R. et al., 2020; Pierozan et al., 2020). More importantly, targeting these PCDs shows promising therapeutic effects for diabetes and diabetes-related diseases (Zhang K. et al., 2019; Hu et al., 2019).

\section{Distinct Forms of PCD IN SC for Transplantation Apoptosis}

Apoptosis is characterized by the breaking up of cell in apoptotic bodies (Nikoletopoulou et al., 2013). In intrinsic pathway of apoptosis, DNA damage can activate p53, and subsequently induce genes involved in apoptosis signaling and execution (Figure 1A) (Hafner et al., 2019). In human ESCs, the stabilization of p53 can suppress the pluripotency of SCs after DNA damage responses (Zhang et al., 2014). In addition, silencing of the proapoptotic gene Puma, which is responsible for p53-dependent apoptosis, can increase pluripotency of iPSCs (Lake et al., 2012; Fu et al., 2020). Moreover, proapoptotic BCL-2 signals and ASPP1, an apoptosis-stimulating protein of $\mathrm{p} 53$, contributed to the induction of apoptosis in HSCs (Yamashita et al., 2015; 2016).

The extrinsic pathway of apoptosis is initiated by docking of death ligands of tumor necrosis factor (TNF) to TNF receptors 1 (TNFR1) (Carneiro and El-Deiry, 2020). TNFa can induce apoptosis in NSCs by upregulating the phosphatidylinositol p38 mitogen-activated protein kinase (p38 MAPK) pathway (Chen et al., 2016). In HSC transplantation for treating malignancies, activation of TNF-a-TNFR1 signaling pathway caused accumulation of reactive oxygen species (ROS) in HSCs and subsequent cell damage (Ishida et al., 2017). In contrast, TNF-a-TNFR2 signaling is important for survival and function of MSCs and endothelial stem/progenitor cells (EPCs), and its deficiency resulted in reduced proliferation rate and diminished immunomodulatory effect of these cells (Beldi et al., 2020a; Beldi et al., 2020b; Naserian et al., 2020; Nouri Barkestani et al., 2021; Razazian et al., 2021).

\section{Autophagy}

Autophagy is a self-degradative process that contributes to removing excessive or misfolded proteins and clearing damaged organelles at critical times (Figure 1B) (Glick et al., 2010; Andrade-Tomaz et al., 2020). The autophagy is triggered by upregulation of AMP activated protein kinase (AMPK) and downregulation of mammalian target of rapamycin complex 1 (mTORC1) (Kim et al., 2011). In ESCs and HSCs, the regulation of AMPK and mTOR kinase is essential to their homeostasis, selfrenewal and pluripotency (Huang et al., 2009; Gong et al., 2018; Suvorova et al., 2019). Additionally, the precise regulation of mTOR by Sox 2 is vital to reprogramming of somatic cells to form iPSCs (Wang S. et al., 2013). The viability and stemness of NSCs and ESCs were also associated with LC3 lipidation, autophagic flux, and formation of autophagosomes (Bialik and Kimchi, 2010; Vázquez et al., 2012; Gu et al., 2019; Wang et al., 2019). Additionally, the autophagy-related gene ATG3 was shown to be a pivotal regulator of mitochondrial homeostasis regulation in ESCs (Liu et al., 2016).

Notably, Dou et al. demonstrated that an amyloid binding peptide with three chaperone-mediated autophagy motifs significantly reduced $\mathrm{A} \beta$ oligomers in iPSC cortical neurons (Dou et al., 2020). Autophagy driven by FOXO3A and FOXO1 also protected HSCs from metabolic stress and guarded ESC identity (Warr et al., 2013; Liu et al., 2017). More importantly, the coordination of autophagy and apoptosis is vital to maintaining homeostasis in BM-MSCs (Zhang et al., 2016).

\section{Necroptosis}

Necroptosis is a programmed form of necrosis mediated by receptor interacting protein kinase $1 / 3$ (RIPK1/3) and mixed lineage kinase domain-like (MLKL) proteins (Figure 1C) (Wang M. et al., 2020; Font-Belmonte, 2020; Yan WT. et al., 2021; Liao et al., 2021). Necroptosis of intestinal SCs triggered bowel inflammation in the pathogenesis of inflammatory bowel disease (Wang R. et al., 2020). In addition, compression triggered necroptosis of nucleus pulposus-derived SCs and inhibiting necroptosis rescued regeneration of degenerated intervertebral discs ( $\mathrm{Hu}$ B. et al., 2020). Furthermore, inhibition of necroptosis is a novel strategy for allogeneic HSCs transplantation and spermatogonial SC-based therapy for male fertility preservation (Matsuzawa-Ishimoto et al., 2017; Xie et al., 2020). Moreover, cellular transplant therapy based on human olfactory SCs ameliorated motor function in Huntington's disease by preventing necroptosis (Bayat et al., 2021). Intriguingly, TNF- $\alpha$ also could function as a proregeneration factor in HSCs that primarily prevented necroptosis rather than apoptosis by activating a p65-nuclear factor $\kappa \mathrm{B}$-dependent gene program (Yamashita and Passegué, 2019).

\section{Pyroptosis}

Pyroptosis is specific PCD mediated by cleavage of gasdermin D (GSDMD) to form membrane pores and activation of cytokines (Figure 1D) (Chu et al., 2020; Chen Y. et al., 2021; Huang Y. et al., 2021). Pyroptosis contributed to the cell death of human cardiac SCs (hCSCs) in an acute hyperglycemic microenvironment, which impaired cardiac regeneration in diabetic hearts (Yadav et al., 2020). The culture media collected from pyroptotic bone marrow-derived macrophages also induced pyroptosis in MSCs (Zhang C. et al., 2020). Additionally, the pyroptosis of neural progenitor cells represented a therapeutic target in Zika virusinduced brain atrophy (He Z. et al., 2020). Moreover, chitosan thermosensitive hydrogel enhanced the therapeutic efficacy of 


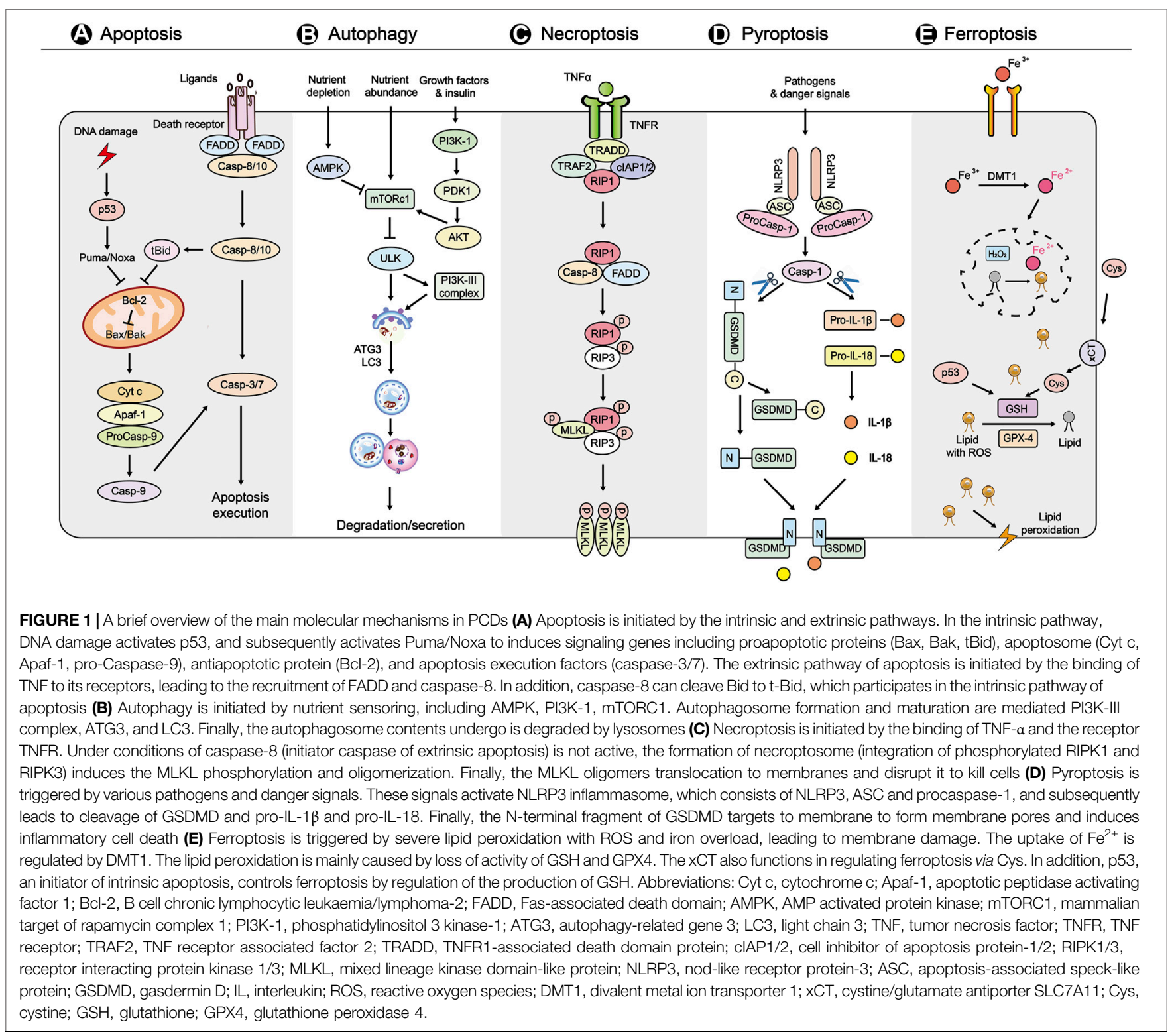

BM-MSCs for myocardial infarction by alleviating pyroptosis of vascular endothelial cells (Liu Y. et al., 2020). Finally, emerging evidence showed that SCs and SC-derived exosomes inhibited pyroptosis and could be used to treat different diseases (Zhang J. et al., 2020; Yan et al., 2020; Chen M.-T. et al., 2021).

\section{Ferroptosis}

Ferroptosis is an iron-dependent form of cell death (Figure 1E) (Stockwell et al., 2017). The iPSC-derived cell modeling of neuroferritinopathy revealed that iron-dependent ferroptosis has a primary role in neuronal aging and degeneration (Cozzi et al., 2019). Also, iron overload (IOL) may induce cellular toxicity in hematopoietic SCs therapy for hematologic malignancies, and IOL reduction may improve outcomes (Leitch et al., 2017). In addition, catecholic flavonol quercetin inhibited erastin-induced ferroptosis in BM-MSCs (Li et al.,
2020). Moreover, in Pelizaeus-Merzbacher disease, the mutant oligodendrocytes of patients exhibited the hallmarks of ferroptosis, and gene correction in patient-derived iPSCs rescued the iron-induced cell death (Nobuta et al., 2019).

The characteristics of distinct kinds of PCD in transplanted SCs provide an in-depth understanding of cell death in SC therapy. Based on the key mediators and crosstalk identified in PCD, the development of highly precise strategies to improve SC survival is possible.

\section{Which Types of PCD Reported IN SC can be Used to Treat Diabetes and Diabetes-Related Diseases?}

Whereas SC therapy represents a highly promising therapeutic strategy for treating diabetes, PCD existed in 
TABLE 1 | Current strategies to prevent PCD of SC for transplantation.

\begin{tabular}{|c|c|c|c|c|c|}
\hline Strategy & Method & Targeting PCD & SC & Application & References \\
\hline \multicolumn{6}{|l|}{ Preconditioning } \\
\hline \multirow[t]{4}{*}{ Hypoxia } & $1 \% \mathrm{O}_{2}$ for $48 \mathrm{~h}$ & Apoptosis & AD-MSCs & Tissue regeneration & Liu et al. (2013) \\
\hline & $1.5 \% \mathrm{O}_{2}$ for $24 \mathrm{~h}$ & Apoptosis & MSCs & $\begin{array}{l}\text { Idiopathic pulmonary } \\
\text { fibrosis }\end{array}$ & Lan et al. (2015) \\
\hline & $5 \% \mathrm{O}_{2}$ for $6 \mathrm{~h}$ & $\begin{array}{l}\text { Apoptosis; } \\
\text { autophagy }\end{array}$ & BM-MSCs & $\begin{array}{l}\text { Diabetic lower-limb } \\
\text { ischemia }\end{array}$ & Liu et al. (2015a) \\
\hline & $5 \% \mathrm{O}_{2}$ for $48 \mathrm{~h}$ & Apoptosis & BM-MSCs & $\begin{array}{l}\text { Diabetic lower-limb } \\
\text { ischemia }\end{array}$ & Liu et al. (2015b) \\
\hline \multirow[t]{2}{*}{ Oxidative stress } & $100 \mathrm{mM} \mathrm{H}_{2} \mathrm{O}_{2}$ for 2 days & Apoptosis & $\begin{array}{l}\text { Cardiac progenitor } \\
\text { cells }\end{array}$ & Heart failure & $\begin{array}{l}\text { Pendergrass et al. } \\
\text { (2013) }\end{array}$ \\
\hline & $50 \mu \mathrm{M} \mathrm{H} \mathrm{O}_{2}$ for $12 \mathrm{~h}$ & Apoptosis & BM-MSCs & Wound healing & Guo et al. (2020b) \\
\hline \multirow[t]{2}{*}{ Heat shock } & $42 \mathrm{C}$ for $1 \mathrm{~h}$ & Apoptosis & UC-MSCs & Acute lung injury & Lv et al. (2021) \\
\hline & $42 \mathrm{C}$ for $1 \mathrm{~h}$ & Apoptosis & BM-MSCs & Premature ovarian failure & Chen et al. (2018) \\
\hline Lipopolysaccharide & $1.0 \mathrm{lg} / \mathrm{mL}$ for $24 \mathrm{~h}$ & Apoptosis & BM-MSCs & $\begin{array}{l}\text { Hypoxia and serum } \\
\text { deprivation }\end{array}$ & Wang et al. (2013a) \\
\hline Melatonin & $5 \mu \mathrm{M}$ for $24 \mathrm{~h}$ & Apoptosis & BM-MSCs & Ischemic kidney & Mias et al. (2008) \\
\hline Oxytocin & $10 \mathrm{nM}$ for $24 \mathrm{~h}$ & Apoptosis & BM-MSCs & $\begin{array}{l}\text { Hypoxia and serum } \\
\text { deprivation }\end{array}$ & Noiseux et al. (2012) \\
\hline Sevoflurane & 2 vol\% for $2 \mathrm{~h}$ & Apoptosis & BM-MSCs & $\begin{array}{l}\text { Hypoxia and serum } \\
\text { deprivation }\end{array}$ & Sun et al. (2014) \\
\hline \multirow[t]{2}{*}{ Resveratrol } & $10 \mu \mathrm{M}$ for $10 \mathrm{~h}$ & Autophagy & ESCs & $\begin{array}{l}\text { Enhancing pluripotency } \\
\text { of SC }\end{array}$ & Suvorova et al. (2019) \\
\hline & $10 \mu \mathrm{M}$ for $2 \mathrm{~h}$ & Apoptosis & ADSC & Type 1 diabetes & Chen et al. (2019b) \\
\hline \multicolumn{6}{|l|}{ Genetic modification } \\
\hline AURKA & Lentivirus vectors transfection & $\begin{array}{l}\text { Apoptosis; } \\
\text { autophagy }\end{array}$ & ADSC & Diabetic wound healing & Yin et al. (2020) \\
\hline VEGF $_{165}$ & Bi-Tet transfection & Apoptosis & ESCs & Cardiac function & Xie et al. (2007) \\
\hline \multirow[t]{2}{*}{ HGF } & Adenoviral vector transfection & Apoptosis & UC-MSCs & Acute liver failure & Tang et al. (2016) \\
\hline & Adenoviral vector transfection & Apoptosis & BM-MSCs & Hepatocirrhosis & Zhang et al. (2018) \\
\hline ERBB4 & Lentivirus vectors transfection & Apoptosis & MSCs & Myocardial infarction & Liang et al. (2015) \\
\hline \multirow[t]{2}{*}{ HIF1a } & Lentivirus vectors transfection & Apoptosis & ADSC & Diabetic wound healing & Xu et al. (2020) \\
\hline & Adenoviral vector transfection & Apoptosis & MSCs & Myocardial infarction & Huang et al. (2014) \\
\hline \multicolumn{6}{|l|}{ 3D cell culturing } \\
\hline 3D-dynamic system & Culturing for $48 \mathrm{~h}$ & Apoptosis & BM-MSCs & Myocardial infarction & Wang et al. (2018a) \\
\hline 3D floating culture & Culturing for 3 days & Apoptosis & MSCs & Enhancing survival of SC & Komatsu et al. (2020) \\
\hline 3D organ culture & $\begin{array}{l}\text { Culture with D-serine and RA for } \\
3 \text { weeks }\end{array}$ & Apoptosis & Spermatogonial SCs & Spermatogenesis & $\begin{array}{l}\text { Modirshanechi et al. } \\
\text { (2020) }\end{array}$ \\
\hline \multicolumn{6}{|l|}{ Co-transplantation } \\
\hline NSCs and OECs & NSCs: OECs = 1:1 & Apoptosis & NSCs & Traumatic brain injury & Liu et al. (2014) \\
\hline EPI-NCSCs and OECs & EPI-NCSCs: OECs = 1:1 & Apoptosis & EPI-NCSCs & Peripheral nerve injury & Zhang et al. (2019b) \\
\hline $\begin{array}{l}\text { BM-MSCs and } \\
\text { monocytes }\end{array}$ & BM-MSCs: monocytes $=1: 30$ & Apoptosis & BM-MSCs & Facial nerve axotomy & Wu et al. (2020a) \\
\hline
\end{tabular}

Abbreviations: SCs, stem cells; MSCs, mesenchymal stem cells; ESCs, embryonic stem cells; AD-MSCs, adipose-derived mesenchymal stem cells; BM-MSCs, bone marrow-derived mesenchymal stem cells; UC-MSCs, umbilical cord-derived mesenchymal stem cells; ADSC, Adipose-derived stem cells; NSCs, neural stem cells; EPI-NCSCs, epidermal neural crest stem cells; OECs, olfactory ensheathing cells; RA, retinoic acid; AURKA, Aurora kinase A; VEGF 165 , vascular endothelial growth factor 165; HGF, hepatocyte growth factor; ERBB4, v-erbb2, avian erythroblastic leukemia viral oncogene homolog 4; HIF1 $\alpha$, hypoxia-inducible factor $1 \alpha$.

SCs hinders the therapeutic effects (Saleem et al., 2019). For example, hyperglycemia increased apoptosis of Adiposederived SCs (ADSCs) and decreased their paracrine function in diabetic retinopathy (Hajmousa et al., 2016; Xu et al., 2020). Furthermore, BM-MSCs from streptozotocininduced diabetic rats showed impaired antiapoptosis, proliferation and paracrine abilities (Jin et al., 2010).

More importantly, overexpression of hypoxia-inducible factor la (HIF1a), a regulator of oxygen homeostasis, significantly alleviated the ADSC apoptosis rate and enhanced diabetic wound closure (Xu et al., 2020). Norepinephrine can also reverse high glucose-induced apoptosis in MSCs through the AKT/BCL-2 pathway
(Kong et al., 2019). The peroxisome proliferator-activated receptor- $\gamma$ agonist pioglitazone (PGZ) is used for management of diabetes (Cho et al., 2019). It was reported that PGZ had a protective effect on compression-mediated apoptosis in MSCs by suppressing mitochondrial apoptosis pathway (Hu et al., 2019).

In addition, autophagy played a protective role in ADSC under high glucose stress (Li et al., 2018). More importantly, the overexpression of Aurora kinase A (AURKA), a cell cycleregulated kinase, enhanced autophagy of ADSCs, decreased apoptosis, and promoted wound healing in diabetic mice (Yin et al., 2020). Also, the inhibition of autophagy significantly promoted high glucose/ROS-mediated apoptosis in ADSCs (Li 
et al., 2018). Furthermore, upregulating autophagy in periodontal ligament SCs partially recovered periodontium tissues in a diabetic rat periodontal trauma model, suggesting the protective role of autophagy for SC transplantation (Zhang $\mathrm{K}$. et al., 2019). Additionally, exosomes derived from MSCs ameliorated type 2 diabetes by activating autophagy via AMPK pathway (He Q. et al., 2020). Moreover, pyroptosis contributed to the cell death of hCSCs in an acute hyperglycemic microenvironment, which impaired cardiac regeneration in diabetic hearts (Yadav et al., 2020).

Although emerging evidence indicates that many forms of PCD play vital roles in the cell death of SCs for treating diabetes and diabetes-related diseases, the identification of necroptosis and ferroptosis remains to be explored further.

\section{Current Strategies to Prevent PCD OF SC for Transplantation Preconditioning}

The benefit of preconditioning of SC was first described in ischemic myocardium, and to date, a variety of preconditioning strategies have been shown to improve SC survival (Table 1) (Sart et al., 2014; Hu and Li, 2018). Hypoxic preconditioning could decrease apoptosis and increased autophagy in MSCs and BM-MSCs (Liu et al., 2013; Liu et al., 2015a; Lan et al., 2015). Exposure to oxidative stress decreased apoptosis of BM-MSCs upon serum withdrawal and oxidative stress (Pendergrass et al., 2013; Guo L. et al., 2020). Furthermore, heat shock pretreatment enhanced repair effects of MSCs for acute lung injury and premature ovarian failure via reducing apoptosis and macrophages (Chen et al., 2018; Lv et al., 2021).

Preconditioning of SCs with pharmacological or chemical agents also improved SCs survival via preventing PCD. For example, lipopolysaccharide (LPS) preconditioning protected MSCs against apoptosis induced by hypoxia and serum deprivation via suppressing the extracellular signalregulated kinase signaling pathway (Wang J. et al., 2013; $\mathrm{Hu}$ and Li, 2018). Preconditioning with melatonin, oxytocin, and sevoflurane also increased the resistance of MSCs to apoptosis and their paracrine activity (Mias et al., 2008; Noiseux et al., 2012; Sun et al., 2014). In addition, pretreatment with resveratrol induced autophagy in ESCs via activation of AMPK/ULK1 pathway (Suvorova et al., 2019). Moreover, TNF- $\alpha$ and other inflammatory mediators preconditioning could increase the survival, proliferation and immunomodulatory effects of MSCs and EPCs (Song et al., 2019; Beldi et al., 2020a; Ferreira et al., 2021; Nouri Barkestani et al., 2021).

\section{Genetic Modification}

Accumulated studies have identified promising therapeutic molecular targets for genetic modification to prevent PCD of SCs. Regarding cardiovascular disease, ESCs transfected with inducible VEGF inhibited apoptosis of transplanted cell and significantly improved the cardiac function (Xie et al., 2007). In addition, overexpressing hepatocyte growth factor (HGF) modulated apoptosis of UC-MSCs and protected animals from acute liver failure (Tang et al., 2016). Also, HGF overexpression enhanced the therapeutic effect of BM-MSC for hepatocirrhosis (Zhang et al., 2018). The transduction of ERBB4 into MSCs also increased apoptotic resistance via activating PI3K/AKT signaling pathway (Liang et al., 2015). Moreover, HIF1a transfection improved the cardiac repair efficiency of MSCs by decreasing cardiomyocytes apoptosis (Huang et al., 2014). Importantly, the genetic upregulation of several pro-survival factors, including Bcl-2, Bcl-xl and Akt1, could increase the long-term survival of transplanted human NSCs (Korshunova et al., 2020).

\section{D Cell Culturing}

Cell culture is conventionally conducted by a two-dimensional (2D) system that often does not adequately replicate the threedimensional (3D) environment, and it is deficient in cell-to-cell interactions (Madl et al., 2018; Seo et al., 2019). The 3D culturing of bone marrow MSCs using a 3D-dynamic system exhibited decreased apoptosis and improved therapeutic effect for cardiac function (Wang Y. et al., 2018). A recently developed 3D culture clump of MSCs/extracellular matrix complexes also showed resistance against apoptosis (Komatsu et al., 2020). Furthermore, the presence of D-serine and retinoic acid in the $3 \mathrm{D}$ organ culture of spermatogonial SCs enhanced its therapeutic effect on spermatogenesis via suppressing apoptotic signaling (Modirshanechi et al., 2020). Moreover, exosomes derived from UC-MSCs under 3D culturing exerted improved osteochondral regeneration activity (Yan and $\mathrm{Wu}, 2020$ ).

\section{Co-Transplantation}

Co-transplantation of SC with other SCs or adult cells can also restore SCs via suppressing PCD. Co-transplantation of NSCs with olfactory ensheathing cells (OECs) attenuated neuronal apoptosis in traumatic brain injury (Liu et al., 2014). Also, the co-transplantation of OECs with epidermal neural crest SCs exerted a beneficial effect upon peripheral nerve injury (Zhang L. et al., 2019). Regarding repairing facial nerve axotomy, the cotransplantation of BM-MSCs and monocytes reduced apoptosis of facial nerve nucleus (Wu L. et al., 2020). Moreover, cotransplantation of ADSCs and stromal vascular fractions improved parathyroid transplantation survival in vitro and in vivo for treating hypoparathyroidism (Cui et al., 2020).

\section{Studies on Promoting SC Survival for Diabetes and Diabetes-Related Diseases}

Regarding treating diabetes and diabetes-related diseases, multiple strategies have also been applied to improve cell survival after SC transplantation. It was reported that the hypoxic preconditioning of BM-MSCs upregulated the antiapoptotic protein $\mathrm{Bcl}-2$, thus promoting endothelial cell proliferation and decreasing the apoptosis of endothelial cells in diabetic rats (Liu et al., 2015b). Also, exposure to short-term hypoxia enhanced islet protective potential of adipose-derived MSCs (AD-MSCs) (Schive et al., 2017). In 
addition, hypoxia pretreatment promoted the AD-MSCs based repair of diabetic erectile dysfunction by increasing the survival of transplanted SCs in host tissues and their expression of regenerative factors (Wang et al., 2015).

Preconditioning with pharmacological or chemical agents has promoted SCs survival for treating diabetes. Preconditioning with resveratrol significantly enhanced the viability and therapeutic effect of ADSC and increased expression of the survival marker $p$-Akt for the treatment of damaged pancreas and liver dysfunction in diabetic rats (Chen et al., 2019a; Chen et al., 2019b). In addition, pretreatment with mitoTEMPO, a mitochondrial ROS scavenger, improved the survival of ADSC in diabetic mice and decreased the limb injury (Lian et al., 2019). Moreover, treatment of MSCs in combination with melatonin decreased the rate of islet cell apoptosis via suppressing apoptotic signaling (Kadry et al., 2018). Also, melatonin preconditioning enhanced the effect of MSCs-derived exosomes on diabetic wound healing by regulating macrophages and targeting the PTEN/AKT pathway (Liu W. et al., 2020). Notably, although metformin, the most commonly used antidiabetic drug, and BM-MSCs treatment individually improve cardiac function in diabetic cardiomyopathy, metformin can reduce the efficacy of MSCs therapy for cardiac repair during diabetic cardiomyopathy by decreasing the survival of transplanted SCs (Ammar et al., 2021).

Genetic modification improved the survival of SCs for treating diabetes and diabetes-related diseases. The overexpression of HIF1a reduced ADSC apoptosis upon high glucose conditions and enhanced the therapeutic effects on diabetic wound healing (Xu et al., 2020). The preconditioning of MSCs with deferoxamine, an iron chelator, increased the stability of HIF1a protein and homing of MSCs in streptozotocin-diabetic rats (Najafi and Sharifi, 2013). Moreover, the overexpression of AURKA promoted the effect of ADSCs on wound healing in diabetic mice via enhancing autophagy of ADSCs and decreasing apoptosis (Yin et al., 2020).

It was also demonstrated that co-culturing and cotransplanting of BM-MSCs and islet reduced islet destruction in vitro and increased anti-inflammatory effects in vivo (Yoshimatsu et al., 2015). Another study reported that islets co-cultured with ADSC reduced apoptosis and improved glucose-stimulated insulin secretion compared with the control group (Gamble et al., 2018). Moreover, the co-transplantation of MSCs and fetal HSCs enhanced engraftment of HSCs and promoted the therapeutic effect in T1DM (Arjmand et al., 2019).

\section{Implications for Future Strategies to Improve SC Therapy for Diabetes and Diabetes-Related Diseases}

Although the necroptosis and ferroptosis in SCs for treating diabetic diseases are rarely reported, recent studies indicated these two types of PCD are primary mechanisms of cell death in islet transplantation, suggesting the potential value of targeting necroptosis and ferroptosis for SC therapy (Zhao et al., 2015; Yao et al., 2020). As mentioned in this review, interactions between different types of PCD also need further study and novel regulators, such as AMPK/mTOR, which coordinate multiple cell death are promising therapeutic targets to improve SC therapy for diabetes and diabetesrelated diseases (Zhang et al., 2016).

Although genetic modification is an efficient method to target $\mathrm{PCD}$, the use of genetic techniques raises some safety concerns (Hu C. et al., 2020). Preconditioning strategies of SCs for transplantation are an attractive alternative to overcome this potential limitation. Increased oxidative stress is considered a major factor to compromise MSCs in diabets models (Fijany et al., 2019). Evidence supporting the benefit of acute preconditioning of SCs with oxidative stress suggests that the application of preconditioning may reduce oxidative stress-induced PCD in diabetic diseases (Pendergrass et al., 2013). Moreover, preconditioning with melatonin showed a significant protective effect on SCs via targeting multiple types of PCD, and melatonin suppressed osteoblasts ferroptosis induced by high glucose in type 2 diabetic osteoporosis (Liu W. et al., 2020; Zhao et al., 2020b; Ma et al., 2020). Thus, melatonin is a promising agent to improve SC survival in transplantation for treating diabetes and diabetes-related diseases.

As $3 \mathrm{D}$ culture systems become more relevant to innate structure and physiology, the ability to adequately replicate the 3D environment experienced by transplanted SCs becomes possible. Studies of 3D cell culturing developed to reduce $\mathrm{PCD}$ of $\mathrm{SCs}$ and improve their therapeutic effects have rapidly advanced (Shimony et al., 2008; Modirshanechi et al., 2020). In addition, a 3D capacitance cell sensor has been developed to monitor cell apoptosis in real-time for 3D cell cultures (Lee et al., 2016). Although methods of $3 \mathrm{D}$ cell culturing of SCs that can be used for treating diabetic diseases have been established, the application of these methods and their benefit requires further exploration.

\section{CONCLUSION}

Extensive and increasing evidence demonstrates that distinct types of PCD contribute to the cell death of SCs, and the inhibition of PCDs can promote the survival of SCs and their therapeutic effects in diabetes and diabetes-related diseases. These findings provide deep insights into the cell death of SCs-based therapy for diabetes and diabetes-related diseases and shed light on the future development of therapeutic strategies.

\section{AUTHOR CONTRIBUTIONS}

QZ wrote the first draft of the manuscript. XW, XH, WZ, XB, YH contributed to manuscript draft review and modification. $\mathrm{KX}$ and 
QZ developed the idea. KX and WY supervised the work. All authors contributed to the article and approved the submitted version.

\section{FUNDING}

This study was funded by the National Natural Science Foundation of China (81772134, 81971891, 82172196, and 81571939), the Research Project on Deepening Innovation

\section{REFERENCES}

Ammar, H. I., Shamseldeen, A. M., Shoukry, H. S., Ashour, H., Kamar, S. S., Rashed, L. A., et al. (2021). Metformin Impairs Homing Ability and Efficacy of Mesenchymal Stem Cells for Cardiac Repair in Streptozotocin-Induced Diabetic Cardiomyopathy in Rats. Am. J. Physiology-Heart Circulatory Physiol. 320, H1290-H1302. doi:10.1152/ajpheart.00317.2020

Andrade-Tomaz, M., De Souza, I., Rocha, C. R. R., and Gomes, L. R. (2020). The Role of Chaperone-Mediated Autophagy in Cell Cycle Control and its Implications in Cancer. Cells 9, 2140. doi:10.3390/cells9092140

Arjmand, B., Goodarzi, P., Aghayan, H. R., Payab, M., Rahim, F., AlaviMoghadam, S., et al. (2019). Co-transplantation of Human Fetal Mesenchymal and Hematopoietic Stem Cells in Type 1 Diabetic Mice Model. Front. Endocrinol. 10, 761. doi:10.3389/fendo.2019.00761

Bayat, A.-H., Saeidikhoo, S., Ebrahimi, V., Mesgar, S., Joneidi, M., Soltani, R., et al. (2021). Bilateral Striatal Transplantation of Human Olfactory Stem Cells Ameliorates Motor Function, Prevents Necroptosis-Induced Cell Death and Improves Striatal Volume in the Rat Model of Huntington's Disease. J. Chem. Neuroanat. 112, 101903. doi:10.1016/j.jchemneu.2020.101903

Bedoui, S., Herold, M. J., and Strasser, A. (2020). Emerging Connectivity of Programmed Cell Death Pathways and its Physiological Implications. Nat. Rev. Mol. Cel Biol. 21, 678-695. doi:10.1038/s41580-020-0270-8

Beldi, G., Bahiraii, S., Lezin, C., Nouri Barkestani, M., Abdelgawad, M. E., Uzan, G., et al. (2020a). TNFR2 Is a Crucial Hub Controlling Mesenchymal Stem Cell Biological and Functional Properties. Front. Cel Dev. Biol. 8, 1408. doi:10.3389/ fcell.2020.596831

Beldi, G., Khosravi, M., Abdelgawad, M. E., Salomon, B. L., Uzan, G., Haouas, H., et al. (2020b). TNFa/TNFR2 Signaling Pathway: an Active Immune Checkpoint for Mesenchymal Stem Cell Immunoregulatory Function. Stem Cel. Res. Ther. 11, 281. doi:10.1186/s13287-020-01740-5

Bialik, S., and Kimchi, A. (2010). Lethal Weapons: DAP-Kinase, Autophagy and Cell Death. Curr. Opin. Cel Biol. 22, 199-205. doi:10.1016/j.ceb.2009.11.004

Biswas, A., and Hutchins, R. (2007). Embryonic Stem Cells. Stem Cell Dev. 16, 213-222. doi:10.1089/scd.2006.0081

Bogliotti, Y. S., Wu, J., Vilarino, M., Okamura, D., Soto, D. A., Zhong, C., et al. (2018). Efficient Derivation of Stable Primed Pluripotent Embryonic Stem Cells from Bovine Blastocysts. Proc. Natl. Acad. Sci. USA 115, 2090-2095. doi:10.1073/pnas.1716161115

Carneiro, B. A., and El-Deiry, W. S. (2020). Targeting Apoptosis in Cancer Therapy. Nat. Rev. Clin. Oncol. 17, 395-417. doi:10.1038/s41571-0200341-y

Chen, M.-T., Zhao, Y.-T., Zhou, L.-Y., Li, M., Zhang, Q., Han, Q., et al. (2021a). Exosomes Derived from Human Umbilical Cord Mesenchymal Stem Cells Enhance Insulin Sensitivity in Insulin Resistant Human Adipocytes. Curr. Med. Sci. 41, 87-93. doi:10.1007/s11596-021-2323-4

Chen, N.-N., Wei, F., Wang, L., Cui, S., Wan, Y., and Liu, S. (2016). Tumor Necrosis Factor Alpha Induces Neural Stem Cell Apoptosis through Activating P38 MAPK Pathway. Neurochem. Res. 41, 3052-3062. doi:10.1007/s11064-0162024-8

Chen, S., Du, K., and Zou, C. (2020). Current Progress in Stem Cell Therapy for Type 1 Diabetes Mellitus. Stem Cel. Res. Ther. 11, 275. doi:10.1186/s13287-02001793-6 and Entrepreneurship Education Reform of Central South University in 2020 (2020-47), and the 2021 College Students' Innovation and Entrepreneurship Project (S20210026020013).

\section{ACKNOWLEDGMENTS}

The authors would like to acknowledge the language-editing service provided by Wordvice.

Chen, T. S., Ju, D. T., Day, C. H., Yeh, Y. L., Chen, R. J., Viswanadha, V. P., et al. (2019a). Protective Effect of Autologous Transplantation of Resveratrol Preconditioned Adipose-derived Stem Cells in the Treatment of Diabetic Liver Dysfunction in Rat Model. J. Tissue Eng. Regen. Med. 13, 1629-1640. doi:10.1002/term. 2917

Chen, T. S., Kuo, C. H., Day, C. H., Pan, L. F., Chen, R. J., Chen, B. C., et al. (2019b). Resveratrol Increases Stem Cell Function in the Treatment of Damaged Pancreas. J. Cel. Physiol. 234, 20443-20452. doi:10.1002/jcp.28646

Chen, X., Wang, Q., Li, X., Wang, Q., Xie, J., and Fu, X. (2018). Heat Shock Pretreatment of Mesenchymal Stem Cells for Inhibiting the Apoptosis of Ovarian Granulosa Cells Enhanced the Repair Effect on ChemotherapyInduced Premature Ovarian Failure. Stem Cel. Res. Ther. 9, 240. doi:10.1186/s13287-018-0964-4

Chen, Y., Li, Y., Guo, L., Hong, J., Zhao, W., Hu, X., et al. (2021b). Bibliometric Analysis of the Inflammasome and Pyroptosis in Brain. Front. Pharmacol. 11, 2315. doi:10.3389/fphar.2020.626502

Cheng, S. Y., Wang, S. C., Lei, M., Wang, Z., and Xiong, K. (2018). Regulatory Role of Calpain in Neuronal Death. Neural Regen. Res. 13, 556-562. doi:10.4103/ 1673-5374.228762

Cho, K. Y., Nakamura, A., Omori, K., Takase, T., Miya, A., Manda, N., et al. (2019). Effect of Switching from Pioglitazone to the Sodium Glucose Co-transporter-2 Inhibitor Dapagliflozin on Body Weight and Metabolism-Related Factors in Patients with Type 2 Diabetes Mellitus: An Open-Label, Prospective, Randomized, Parallel-Group Comparison. Diabetes Obes. Metab. 21, 710-714. doi:10.1111/dom.13557

Chu, J., Liu, C. X., Song, R., and Li, Q. L. (2020). Ferrostatin-1 Protects HT-22 Cells from Oxidative Toxicity. Neural Regen. Res. 15, 528-536. doi:10.4103/16735374.266060

Cozzi, A., Orellana, D. I., Santambrogio, P., Rubio, A., Cancellieri, C., Giannelli, S., et al. (2019). Stem Cell Modeling of Neuroferritinopathy Reveals Iron as a Determinant of Senescence and Ferroptosis during Neuronal Aging. Stem Cel Rep. 13, 832-846. doi:10.1016/j.stemcr.2019.09.002

Cui, Q., Zhang, D., Kong, D., Tang, J., Liao, X., Yang, Q., et al. (2020). Cotransplantation with Adipose-Derived Cells to Improve Parathyroid Transplantation in a Mice Model. Stem Cel. Res. Ther. 11, 200. doi:10.1186/ s13287-020-01733-4

Dou, J., Su, P., Xu, C., Wen, Z., Mao, Z., and Li, W. (2020). Targeting Hsc70-Based Autophagy to Eliminate Amyloid $\beta$ Oligomers. Biochem. Biophysical Res. Commun. 524, 923-928. doi:10.1016/j.bbrc.2020.02.016

Fatima, A., Rrez-Garcia, R., and Vilchez, D. (2019). Guti, \#233Induced Pluripotent Stem Cells from Huntington's Disease Patients: a Promising Approach to Define and Correct Disease-Related Alterations. Neural Regen. Res. 14, 769-770.

Ferreira, J., Teixeira, G. Q., Teixeira, G., Neto, e., Ribeiro-Machado, c., Silva, A. et al. (2021). IL-1 $\beta$-pre-conditioned Mesenchymal Stem/stromal Cells' Secretome Modulates the Inflammatory Response and Aggrecan Deposition in Intervertebral Disc. eCM 41, 431-543. doi:10.22203/ecm.v041a28

Fijany, A., Sayadi, L. R., Khoshab, N., Banyard, D. A., Shaterian, A., Alexander, M., et al. (2019). Mesenchymal Stem Cell Dysfunction in Diabetes. Mol. Biol. Rep. 46, 1459-1475. doi:10.1007/s11033-018-4516-x

Font-Belmonte, E. (2020). Gonz, \#225, Lez-Rodr, \#237, Guez, P., Fern, \#225, NdezL, \#243, and Pez, ANecroptosis in Global Cerebral Ischemia: a Role for Endoplasmic Reticulum Stress. Neural Regen. Res. 15, 455-456. 
Fu, X., Wu, S., Li, B., Xu, Y., and Liu, J. (2020). Functions of P53 in Pluripotent Stem Cells. Protein Cell 11, 71-78. doi:10.1007/s13238-019-00665-x

Gamble, A., Pawlick, R., Pepper, A. R., Bruni, A., Adesida, A., Senior, P. A., et al. (2018). Improved Islet Recovery and Efficacy through Co-culture and Cotransplantation of Islets with Human Adipose-Derived Mesenchymal Stem Cells. PLoS One 13, e0206449. doi:10.1371/journal.pone.0206449

Glick, D., Barth, S., and Macleod, K. F. (2010). Autophagy: Cellular and Molecular Mechanisms. J. Pathol. 221, 3-12. doi:10.1002/path.2697

Gong, J., Gu, H., Zhao, L., Wang, L., Liu, P., Wang, F., et al. (2018). Phosphorylation of ULK1 by AMPK Is Essential for Mouse Embryonic Stem Cell Self-Renewal and Pluripotency. Cell Death Dis 9, 38. doi:10.1038/ s41419-017-0054-Z

Gu, H., Shi, X., Liu, C., Wang, C., Sui, N., Zhao, Y., et al. (2019). USP8 Maintains Embryonic Stem Cell Stemness via Deubiquitination of EPG5. Nat. Commun. 10, 1465. doi:10.1038/s41467-019-09430-4

Guo, L., Du, J., Yuan, D.-F., Zhang, Y., Zhang, S., Zhang, H.-C., et al. (2020b). Optimal H2O2 Preconditioning to Improve Bone Marrow Mesenchymal Stem Cells' Engraftment in Wound Healing. Stem Cel. Res. Ther. 11, 434. doi:10.1186/ s13287-020-01910-5

Guo, L. M., Wang, Z., Li, S. P., Wang, M., Yan, W. T., Liu, F. X., et al. (2020a). RIP3/ MLKL-mediated Neuronal Necroptosis Induced by Methamphetamine at $39^{\circ} \mathrm{C}$. Neural Regen. Res. 15, 865-874. doi:10.4103/1673-5374.268902

Gurusamy, N., Alsayari, A., Rajasingh, S., and Rajasingh, J. (2018). Adult Stem Cells for Regenerative Therapy. Prog. Mol. Biol. Transl. Sci. 160, 1-22. doi:10.1016/bs.pmbts.2018.07.009

Hafner, A., Bulyk, M. L., Jambhekar, A., and Lahav, G. (2019). The Multiple Mechanisms that Regulate P53 Activity and Cell Fate. Nat. Rev. Mol. Cel Biol. 20, 199-210. doi:10.1038/s41580-019-0110-x

Hajmousa, G., Elorza, A. A., Nies, V. J. M., Jensen, E. L., Nagy, R. A., and Harmsen, M. C. (2016). Hyperglycemia Induces Bioenergetic Changes in AdiposeDerived Stromal Cells while Their Pericytic Function Is Retained. Stem Cell Dev. 25, 1444-1453. doi:10.1089/scd.2016.0025

He, Q., Wang, L., Zhao, R., Yan, F., Sha, S., Cui, C., et al. (2020a). Mesenchymal Stem Cell-Derived Exosomes Exert Ameliorative Effects in Type 2 Diabetes by Improving Hepatic Glucose and Lipid Metabolism via Enhancing Autophagy. Stem Cel. Res. Ther. 11, 223. doi:10.1186/s13287-020-01731-6

He, Z., An, S., Chen, J., Zhang, S., Tan, C., Yu, J., et al. (2020b). Neural Progenitor Cell Pyroptosis Contributes to Zika Virus-Induced Brain Atrophy and Represents a Therapeutic Target. Proc. Natl. Acad. Sci. USA 117, 23869-23878. doi:10.1073/pnas.2007773117

Ho, T. T., Warr, M. R., Adelman, E. R., Lansinger, O. M., Flach, J., Verovskaya, E. V., et al. (2017). Autophagy Maintains the Metabolism and Function of Young and Old Stem Cells. Nature 543, 205-210. doi:10.1038/nature21388

Hu, B., Zhang, S., Liu, W., Wang, P., Chen, S., Lv, X., et al. (2020a). Inhibiting Heat Shock Protein 90 Protects Nucleus Pulposus-Derived Stem/Progenitor Cells from Compression-Induced Necroptosis and Apoptosis. Front Cel Dev Biol 8, 685. doi:10.3389/fcell.2020.00685

$\mathrm{Hu}, \mathrm{C}$., and Li, L. (2018). Preconditioning Influences Mesenchymal Stem Cell Properties In Vitro and In Vivo. J. Cel. Mol. Med. 22, 1428-1442. doi:10.1111/ jcmm.13492

Hu, C., Wu, Z., and Li, L. (2020b). Pre-treatments Enhance the Therapeutic Effects of Mesenchymal Stem Cells in Liver Diseases. J. Cel. Mol. Med. 24, 40-49. doi: $10.1111 /$ jcmm. 14788

Hu, X.-M., Zhang, Q., Zhou, R.-X., Wu, Y.-L., Li, Z.-X., Zhang, D.-Y., et al. (2021). Programmed Cell Death in Stem Cell-Based Therapy: Mechanisms and Clinical Applications. Wjsc 13, 386-415. doi:10.4252/wjsc.v13.15.386

Hu, Y., Huang, L., Shen, M., Liu, Y., Liu, G., Wu, Y., et al. (2019). Pioglitazone Protects Compression-Mediated Apoptosis in Nucleus Pulposus Mesenchymal Stem Cells by Suppressing Oxidative Stress. Oxid. Med. Cel. Longev. 2019, 4764071. doi:10.1155/2019/4764071

Huang, B., Qian, J., Ma, J., Huang, Z., Shen, Y., Chen, X., et al. (2014). Myocardial Transfection of Hypoxia-Inducible Factor-1a and Co-transplantation of Mesenchymal Stem Cells Enhance Cardiac Repair in Rats with Experimental Myocardial Infarction. Stem Cel. Res. Ther. 5, 22. doi:10.1186/ scrt410

Huang, J., Zhang, Y., Bersenev, A., O'Brien, W. T., Tong, W., Emerson, S. G., et al. (2009). Pivotal Role for Glycogen Synthase Kinase-3 in Hematopoietic Stem Cell Homeostasis in Mice. J. Clin. Invest. 119, 3519-3529. doi:10.1172/JCI40572
Huang, Q., Ding, Y., Yu, J.-G., Li, J., Xiang, Y., and Tao, N. (2021a). Induction of Differentiation of Mesenchymal Stem Cells into Retinal Pigment Epithelial Cells for Retinal Regeneration by Using Ciliary Neurotrophic Factor in Diabetic Rats. Curr. Med. Sci. 41, 145-152. doi:10.1007/s11596021-2329-y

Huang, Y., Wang, S., Huang, F., Zhang, Q., Qin, B., Liao, L., et al. (2021b). c-FLIP Regulates Pyroptosis in Retinal Neurons Following Oxygen-Glucose Deprivation/recovery via a GSDMD-Mediated Pathway. Ann. Anat. Anatomischer Anzeiger 235, 151672. doi:10.1016/j.anat.2020.151672

Ishida, T., Suzuki, S., Lai, C. Y., Yamazaki, S., Kakuta, S., Iwakura, Y., et al. (2017). Pre-Transplantation Blockade of TNF- $\alpha$-Mediated Oxygen Species Accumulation Protects Hematopoietic Stem Cells. Stem Cells 35, 989-1002. doi:10.1002/stem.2524

Jin, P., Zhang, X., Wu, Y., Li, L., Yin, Q., Zheng, L., et al. (2010). StreptozotocinInduced Diabetic Rat-Derived Bone Marrow Mesenchymal Stem Cells Have Impaired Abilities in Proliferation, Paracrine, Antiapoptosis, and Myogenic Differentiation. Transplant. Proc. 42, 2745-2752. doi:10.1016/ j.transproceed.2010.05.145

Kadry, S. M., El-Dakdoky, M. H., Haggag, N. Z., Rashed, L. A., and Hassen, M. T. (2018). Melatonin Improves the Therapeutic Role of Mesenchymal Stem Cells in Diabetic Rats. Toxicol. Mech. Methods 28, 529-538. doi:10.1080/ 15376516.2018.1471634

Kim, J., Kundu, M., Viollet, B., and Guan, K.-L. (2011). AMPK and mTOR Regulate Autophagy through Direct Phosphorylation of Ulk1. Nat. Cel Biol. 13, 132-141. doi:10.1038/ncb2152

Komatsu, N., Kajiya, M., Morimoto, S., Motoike, S., Yoshii, H., Iwata, T., et al. (2020). Cox2-mediated PGE2 Production via p38/JNK-C-Fos Signaling Inhibits Cell Apoptosis in 3D Floating Culture Clumps of Mesenchymal Stem Cell/ extracellular Matrix Complexes. Biochem. Biophysical Res. Commun. 530, 448-454. doi:10.1016/j.bbrc.2020.05.100

Kong, Y., Cheng, L., Ma, L., Li, H., Cheng, B., and Zhao, Y. (2019). Norepinephrine Protects against Apoptosis of Mesenchymal Stem Cells Induced by High Glucose. J. Cel. Physiol. 234, 20801-20815. doi:10.1002/jcp.28686

Korshunova, I., Rhein, S., García-González, D., Stölting, I., Pfisterer, U., Barta, A., et al. (2020). Genetic Modification Increases the Survival and the Neuroregenerative Properties of Transplanted Neural Stem Cells. JCI Insight 5. doi:10.1172/jci.insight. 126268

Lake, B. B., Fink, J., Klemetsaune, L., Fu, X., Jeffers, J. R., Zambetti, G. P., et al. (2012). Context-Dependent Enhancement of Induced Pluripotent Stem Cell Reprogramming by Silencing Puma. Stem Cells 30, 888-897. doi:10.1002/ stem.1054

Lan, Y.-W., Choo, K.-B., Chen, C.-M., Hung, T.-H., Chen, Y.-B., Hsieh, C.-H., et al. (2015). Hypoxia-preconditioned Mesenchymal Stem Cells Attenuate Bleomycin-Induced Pulmonary Fibrosis. Stem Cel. Res. Ther. 6, 97. doi:10.1186/s13287-015-0081-6

Lee, S.-M., Han, N., Lee, R., Choi, I.-H., Park, Y.-B., Shin, J.-S., et al. (2016). Realtime Monitoring of 3D Cell Culture Using a 3D Capacitance Biosensor. Biosens. Bioelectron. 77, 56-61. doi:10.1016/j.bios.2015.09.005

Leitch, H. A., Fibach, E., and Rachmilewitz, E. (2017). Toxicity of Iron Overload and Iron Overload Reduction in the Setting of Hematopoietic Stem Cell Transplantation for Hematologic Malignancies. Crit. Rev. Oncology/ Hematology 113, 156-170. doi:10.1016/j.critrevonc.2017.03.002

Li, Q., Yin, Y., Zheng, Y., Chen, F., and Jin, P. (2018). Inhibition of Autophagy Promoted High glucose/ROS-Mediated Apoptosis in ADSCs. Stem Cel. Res. Ther. 9, 289. doi:10.1186/s13287-018-1029-4

Li, X., Zeng, J., Liu, Y., Liang, M., Liu, Q., Li, Z., et al. (2020). Inhibitory Effect and Mechanism of Action of Quercetin and Quercetin Diels-Alder Anti-dimer on Erastin-Induced Ferroptosis in Bone Marrow-Derived Mesenchymal Stem Cells. Antioxidants 9, 205. doi:10.3390/antiox9030205

Lian, K., Wang, Q., Zhao, S., Yang, M., Chen, G., Chen, Y., et al. (2019). Pretreatment of Diabetic Adipose-Derived Stem Cells with mitoTEMPO Reverses Their Defective Proangiogenic Function in Diabetic Mice with Critical Limb Ischemia. Cel Transpl. 28, 1652-1663. doi:10.1177/ 0963689719885076

Liang, X., Ding, Y., Zhang, Y., Chai, Y.-H., He, J., Chiu, S.-M., et al. (2015). Activation of NRG1-ERBB4 Signaling Potentiates Mesenchymal Stem CellMediated Myocardial Repairs Following Myocardial Infarction. Cel Death Dis 6, e1765. doi:10.1038/cddis.2015.91 
Liao, L.-S., Lu, S., Yan, W.-T., Wang, S.-C., Guo, L.-M., Yang, Y.-D., et al. (2021). The Role of HSP90a in Methamphetamine/Hyperthermia-Induced Necroptosis in Rat Striatal Neurons. Front. Pharmacol. 12, 716394. doi:10.3389/fphar.2021.716394

Liu, J., Hao, H., Huang, H., Tong, C., Ti, D., Dong, L., et al. (2015a). Hypoxia Regulates the Therapeutic Potential of Mesenchymal Stem Cells through Enhanced Autophagy. The Int. J. Lower Extremity Wounds 14, 63-72. doi:10.1177/1534734615573660

Liu, J., Hao, H., Xia, L., Ti, D., Huang, H., Dong, L., et al. (2015b). Hypoxia Pretreatment of Bone Marrow Mesenchymal Stem Cells Facilitates Angiogenesis by Improving the Function of Endothelial Cells in Diabetic Rats with Lower Ischemia. PLoS One 10, e0126715. doi:10.1371/ journal.pone. 0126715

Liu, K., Zhao, Q., Liu, P., Cao, J., Gong, J., Wang, C., et al. (2016). ATG3-dependent Autophagy Mediates Mitochondrial Homeostasis in Pluripotency Acquirement and Maintenance. Autophagy 12, 2000-2008. doi:10.1080/ 15548627.2016 .1212786

Liu, L., Gao, J., Yuan, Y., Chang, Q., Liao, Y., and Lu, F. (2013). Hypoxia Preconditioned Human Adipose Derived Mesenchymal Stem Cells Enhance Angiogenic Potential via Secretion of Increased VEGF and bFGF. Cell Biol. Int. 37, 551-560. doi:10.1002/cbin.10097

Liu, P., Liu, K., Gu, H., Wang, W., Gong, J., Zhu, Y., et al. (2017). High Autophagic Flux Guards ESC Identity through Coordinating Autophagy Machinery Gene Program by FOXO1. Cell Death Differ 24, 1672-1680. doi:10.1038/cdd.2017.90

Liu, S.-J., Zou, Y., Belegu, V., Lv, L.-Y., Lin, N., Wang, T.-Y., et al. (2014). Cografting of neural stem cells with olfactory en sheathing cells promotes neuronal restoration in traumatic brain injury with an anti-inflammatory mechanism. J. Neuroinflammation 11, 66. doi:10.1186/1742-2094-11-66

Liu, W., Yu, M., Xie, D., Wang, L., Ye, C., Zhu, Q., et al. (2020a). Melatoninstimulated MSC-Derived Exosomes Improve Diabetic Wound Healing through Regulating Macrophage M1 and M2 Polarization by Targeting the PTEN/AKT Pathway. Stem Cel. Res. Ther. 11, 259. doi:10.1186/s13287-020-01756-x

Liu, Y., Li, P., Qiao, C., Wu, T., Sun, X., Wen, M., et al. (2020b). Chitosan Hydrogel Enhances the Therapeutic Efficacy of Bone Marrow-Derived Mesenchymal Stem Cells for Myocardial Infarction by Alleviating Vascular Endothelial Cell Pyroptosis. J. Cardiovasc. Pharmacol. 75, 75-83. doi:10.1097/ fjc. 0000000000000760

Lv, H., Yuan, X., Zhang, J., Lu, T., Yao, J., Zheng, J., et al. (2021). Heat Shock Preconditioning Mesenchymal Stem Cells Attenuate Acute Lung Injury via Reducing NLRP3 Inflammasome Activation in Macrophages. Stem Cel. Res. Ther. 12, 290. doi:10.1186/s13287-021-02328-3

Ma, H., Wang, X., Zhang, W., Li, H., Zhao, W., Sun, J., et al. (2020). Melatonin Suppresses Ferroptosis Induced by High Glucose via Activation of the Nrf2/ HO-1 Signaling Pathway in Type 2 Diabetic Osteoporosis. Oxid. Med. Cel. Longev. 2020, 9067610. doi:10.1155/2020/9067610

Madl, C. M., Heilshorn, S. C., and Blau, H. M. (2018). Bioengineering Strategies to Accelerate Stem Cell Therapeutics. Nature 557, 335-342. doi:10.1038/s41586018-0089-z

Manzar, G. S., Kim, E.-M., and Zavazava, N. (2017). Demethylation of Induced Pluripotent Stem Cells from Type 1 Diabetic Patients Enhances Differentiation into Functional Pancreatic $\beta$ Cells. J. Biol. Chem. 292, 14066-14079. doi:10.1074/jbc.m117.784280

Mastri, M., Lin, H., and Lee, T. (2014). Enhancing the Efficacy of Mesenchymal Stem Cell Therapy. Wjsc 6, 82-93. doi:10.4252/wjsc.v6.i2.82

Matsuzawa-Ishimoto, Y., Shono, Y., Gomez, L. E., Hubbard-Lucey, V. M., Cammer, M., Neil, J., et al. (2017). Autophagy Protein ATG16L1 Prevents Necroptosis in the Intestinal Epithelium. J. Exp. Med. 214, 3687-3705. doi:10.1084/jem.20170558

Mcelhinney, J. M. W. R., Hasan, A., and Sajini, A. A. (2020). The Epitranscriptome Landscape of Small Noncoding RNAs in Stem Cells. Stem Cells 38, 1216-1228. doi:10.1002/stem.3233

Mias, C., Trouche, E., Seguelas, M. H., Calcagno, F., Dignat-George, F., Sabatier, F., et al. (2008). Ex Vivo Pretreatment with Melatonin Improves Survival, Proangiogenic/Mitogenic Activity, and Efficiency of Mesenchymal Stem Cells Injected into Ischemic Kidney. Stem Cells 26, 1749-1757. doi:10.1634/ stemcells.2007-1000
Modirshanechi, G., Eslampour, M. A., and Abdolmaleki, Z. (2020). Agonist and Antagonist NMDA Receptor Effect on Cell Fate during Germ Cell Differentiation and Regulate Apoptotic Process in 3D Organ Culture. Andrologia 52, e13764. doi:10.1111/and.13764

Najafi, R., and Sharifi, A. M. (2013). Deferoxamine Preconditioning Potentiates Mesenchymal Stem Cell Homingin Vitroand in Streptozotocin-Diabetic Rats. Expert Opin. Biol. Ther. 13, 959-972. doi:10.1517/14712598.2013.782390

Naserian, S., Abdelgawad, M. E., Afshar Bakshloo, M., Ha, G., Arouche, N., Cohen, J. L., et al. (2020). The TNF/TNFR2 Signaling Pathway Is a Key Regulatory Factor in Endothelial Progenitor Cell Immunosuppressive Effect. Cell Commun Signal 18, 94. doi:10.1186/s12964-020-00564-3

Nikoletopoulou, V., Markaki, M., Palikaras, K., and Tavernarakis, N. (2013). Crosstalk between Apoptosis, Necrosis and Autophagy. Biochim. Biophys. Acta (Bba) - Mol. Cel Res. 1833, 3448-3459. doi:10.1016/j.bbamcr.2013.06.001

Nobuta, H., Yang, N., Ng, Y. H., Marro, S. G., Sabeur, K., Chavali, M., et al. (2019). Oligodendrocyte Death in Pelizaeus-Merzbacher Disease Is Rescued by Iron Chelation. Cell Stem Cell 25, 531-541. doi:10.1016/j.stem.2019.09.003

Noiseux, N., Borie, M., Desnoyers, A., Menaouar, A., Stevens, L. M., Mansour, S., et al. (2012). Preconditioning of Stem Cells by Oxytocin to Improve Their Therapeutic Potential. Endocrinology 153, 5361-5372. doi:10.1210/en.20121402

Nouri Barkestani, M., Shamdani, S., Afshar Bakshloo, M., Arouche, N., Bambai, B., Uzan, G., et al. (2021). TNFa Priming through its Interaction with TNFR2 Enhances Endothelial Progenitor Cell Immunosuppressive Effect: new hope for Their Widespread Clinical Application. Cel Commun Signal 19, 1. doi:10.1186/ s12964-020-00683-x

Pendergrass, K. D., Boopathy, A. V., Seshadri, G., Maiellaro-Rafferty, K., Che, P. L., Brown, M. E., et al. (2013). Acute Preconditioning of Cardiac Progenitor Cells with Hydrogen Peroxide Enhances Angiogenic Pathways Following IschemiaReperfusion Injury. Stem Cell Dev. 22, 2414-2424. doi:10.1089/scd.2012.0673

Pierozan, P., Cattani, D., and Karlsson, O. (2020). Hippocampal Neural Stem Cells Are More Susceptible to the Neurotoxin BMAA Than Primary Neurons: Effects on Apoptosis, Cellular Differentiation, Neurite Outgrowth, and DNA Methylation. Cel Death Dis 11, 910. doi:10.1038/s41419-020-03093-6

Qin, B., Zhang, Q., Chen, D., Yu, H. Y., Luo, A. X., Suo, L. P., et al. (2021). Extracellular Vesicles Derived from Mesenchymal Stem Cells: A Platform that Can Be Engineered. Histol. Histopathol. 36, 615-632. doi:10.14670/HH-18-297

Razazian, M., Khosravi, M., Bahiraii, S., Uzan, G., Shamdani, S., and Naserian, S. (2021). Differences and Similarities between Mesenchymal Stem Cell and Endothelial Progenitor Cell Immunoregulatory Properties against $\mathrm{T}$ Cells. Wjsc 13, 971-984. doi:10.4252/wjsc.v13.i8.971

Saleem, M., Sabir, S., Akhtar, M. F., Zahid, S., Niazi, S. G., Naeem, M., et al. (2019). Stem Cell Therapy for Diabetes Mellitus: Recent Progress and Hurdles. Crit. Rev. Eukaryot. Gene Expr. 29, 471-482. doi:10.1615/ critreveukaryotgeneexpr.2019025723

Sart, S., Ma, T., and Li, Y. (2014). Preconditioning Stem Cells for In Vivo Delivery. BioResearch Open Access 3, 137-149. doi:10.1089/biores.2014.0012

Schive, S. W., Mirlashari, M. R., Hasvold, G., Wang, M., Josefsen, D., Gullestad, H. P., et al. (2017). Human Adipose-Derived Mesenchymal Stem Cells Respond to Short-Term Hypoxia by Secreting Factors Beneficial for Human Islets In Vitro and Potentiate Antidiabetic Effect In Vivo. Cell Med 9, 103-116. doi:10.3727/ $215517917 \times 693401$

Seo, Y., Shin, T.-H., and Kim, H.-S. (2019). Current Strategies to Enhance Adipose Stem Cell Function: An Update. Ijms 20, 3827. doi:10.3390/ijms20153827

Shimony, N., Avrahami, I., Gorodetsky, R., Elkin, G., Tzukert, K., Zangi, L., et al. (2008). A 3D Rotary Renal and Mesenchymal Stem Cell Culture Model Unveils Cell Death Mechanisms Induced by Matrix Deficiency and Low Shear Stress. Nephrol. Dial. Transplant. 23, 2071-2080. doi:10.1093/ $\mathrm{ndt} / \mathrm{gfn} 062$

Song, W.-J., Li, Q., Ryu, M.-O., Nam, A., An, J.-H., Jung, Y. C., et al. (2019). Canine Adipose Tissue-Derived Mesenchymal Stem Cells Pre-treated with TNF-Alpha Enhance Immunomodulatory Effects in Inflammatory Bowel Disease in Mice. Res. Vet. Sci. 125, 176-184. doi:10.1016/j.rvsc.2019.06.012

Stockwell, B. R., Friedmann Angeli, J. P., Bayir, H., Bush, A. I., Conrad, M., Dixon, S. J., et al. (2017). Ferroptosis: A Regulated Cell Death Nexus Linking Metabolism, Redox Biology, and Disease. Cell 171, 273-285. doi:10.1016/ j.cell.2017.09.021 
Sun, X., Fang, B., Zhao, X., Zhang, G., and Ma, H. (2014). Preconditioning of Mesenchymal Stem Cells by Sevoflurane to Improve Their Therapeutic Potential. PLoS One 9, e90667. doi:10.1371/journal.pone.0090667

Suvorova, I. I., Knyazeva, A. R., Petukhov, A. V., Aksenov, N. D., and Pospelov, V. A. (2019). Resveratrol Enhances Pluripotency of Mouse Embryonic Stem Cells by Activating AMPK/Ulk1 Pathway. Cel Death Discov. 5, 61. doi:10.1038/ s41420-019-0137-y

Tang, Y., Li, Q., Meng, F., Huang, X., Li, C., Zhou, X., et al. (20162016). Therapeutic Potential of HGF-Expressing Human Umbilical Cord Mesenchymal Stem Cells in Mice with Acute Liver Failure. Int. J. Hepatol. 2016, 5452487. doi:10.1155/ 2016/5452487

Vázquez, P., Arroba, A. I., Cecconi, F., De La Rosa, E. J., Boya, P., and De Pablo, F. (2012). Atg5 and Ambra1 Differentially Modulate Neurogenesis in Neural Stem Cells. Autophagy 8, 187-199. doi:10.4161/auto.8.2.18535

Wang, J., Li, Z., Zhang, Y., Liu, X., Chen, L., and Chen, Y. (2013a). CX43 Change in LPS Preconditioning against Apoptosis of Mesenchymal Stem Cells Induced by Hypoxia and Serum Deprivation Is Associated with ERK Signaling Pathway. Mol. Cel. Biochem. 380, 267-275. doi:10.1007/s11010-013-1683-x

Wang, M., Liang, X., Cheng, M., Yang, L., Liu, H., Wang, X., et al. (2019). Homocysteine Enhances Neural Stem Cell Autophagy in In Vivo and In Vitro Model of Ischemic Stroke. Cel Death Dis 10, 561. doi:10.1038/s41419019-1798-4

Wang, M., Wan, H., Wang, S., Liao, L., Huang, Y., Guo, L., et al. (2020a). RSK3 Mediates Necroptosis by Regulating Phosphorylation of RIP3 in Rat Retinal Ganglion Cells. J. Anat. 237, 29-47. doi:10.1111/joa.13185

Wang, R., Li, H., Wu, J., Cai, Z.-Y., Li, B., Ni, H., et al. (2020b). Gut Stem Cell Necroptosis by Genome Instability Triggers Bowel Inflammation. Nature 580, 386-390. doi:10.1038/s41586-020-2127-x

Wang, S., Xia, P., Ye, B., Huang, G., Liu, J., and Fan, Z. (2013b). Transient Activation of Autophagy via Sox2-Mediated Suppression of mTOR Is an Important Early Step in Reprogramming to Pluripotency. Cell Stem Cell 13, 617-625. doi:10.1016/j.stem.2013.10.005

Wang, X., Liu, C., Li, S., Xu, Y., Chen, P., Liu, Y., et al. (2015). Hypoxia Precondition Promotes Adipose-Derived Mesenchymal Stem Cells Based Repair of Diabetic Erectile Dysfunction via Augmenting Angiogenesis and Neuroprotection. PLoS One 10, e0118951. doi:10.1371/journal.pone.0118951

Wang, Y., Zhang, J., Qin, Z., Fan, Z., Lu, C., Chen, B., et al. (2018a). Preparation of High Bioactivity Multilayered Bone-Marrow Mesenchymal Stem Cell Sheets for Myocardial Infarction Using a 3D-Dynamic System. Acta Biomater. 72, 182-195. doi:10.1016/j.actbio.2018.03.052

Wang, Z., Guo, L.-M., Wang, S.-C., Chen, D., Yan, J., Liu, F.-X., et al. (2018b). Progress in Studies of Necroptosis and its Relationship to Disease Processes. Pathol. - Res. Pract. 214, 1749-1757. doi:10.1016/j.prp.2018.09.002

Warr, M. R., Binnewies, M., Flach, J., Reynaud, D., Garg, T., Malhotra, R., et al. (2013). FOXO3A Directs a Protective Autophagy Program in Haematopoietic Stem Cells. Nature 494, 323-327. doi:10.1038/nature11895

Wu, L., Han, D., Jiang, J., Xie, X., Zhao, X., Ke, T., et al. (2020a). Co-transplantation of Bone Marrow Mesenchymal Stem Cells and Monocytes in the Brain Stem to Repair the Facial Nerve Axotomy. Eur. J. Histochem. 64, 3136. doi:10.4081/ ejh.2020.3136

Wu, X., Hu, X., Zhang, Q., Liu, F., and Xiong, K. (2020b). Regulatory Role of Chinese Herbal Medicine in Regulated Neuronal Death. CNS Neurol. Disord. Drug Targets 19, 1-21. doi:10.2174/1871527319666200730165011

Xie, X., Cao, F., Sheikh, A. Y., Li, Z., Connolly, A. J., Pei, X., et al. (2007). Genetic Modification of Embryonic Stem Cells with VEGF Enhances Cell Survival and Improves Cardiac Function. Cloning and Stem Cells 9, 549-563. doi:10.1089/ clo.2007.0032

Xie, Y., Chen, H., Luo, D., Yang, X., Yao, J., Zhang, C., et al. (2020). Inhibiting Necroptosis of Spermatogonial Stem Cell as a Novel Strategy for Male Fertility Preservation. Stem Cell Dev. 29, 475-487. doi:10.1089/scd.2019.0220

Xu, J., Liu, X., Zhao, F., Zhang, Y., and Wang, Z. (2020). HIF1a Overexpression Enhances Diabetic Wound Closure in High Glucose and Low Oxygen Conditions by Promoting Adipose-Derived Stem Cell Paracrine Function and Survival. Stem Cel. Res. Ther. 11, 148. doi:10.1186/s13287-020-01654-2

Yadav, S. K., Kambis, T. N., Kar, S., Park, S. Y., and Mishra, P. K. (2020). MMP9 Mediates Acute Hyperglycemia-Induced Human Cardiac Stem Cell Death by Upregulating Apoptosis and Pyroptosis In Vitro. Cel Death Dis 11, 186. doi:10.1038/s41419-020-2367-6
Yamashita, M., Nitta, E., and Suda, T. (2015). Aspp1 Preserves Hematopoietic Stem Cell Pool Integrity and Prevents Malignant Transformation. Cell stem cell 17, 23-34. doi:10.1016/j.stem.2015.05.013

Yamashita, M., Nitta, E., and Suda, T. (2016). Regulation of Hematopoietic Stem Cell Integrity through P53 and its Related Factors. Ann. N.Y. Acad. Sci. 1370, 45-54. doi:10.1111/nyas.12986

Yamashita, M., and Passegué, E. (2019). TNF- $a$ Coordinates Hematopoietic Stem Cell Survival and Myeloid Regeneration. Cell Stem Cell 25, 357-372. doi:10.1016/j.stem.2019.05.019

Yan, B., Zhang, Y., Liang, C., Liu, B., Ding, F., Wang, Y., et al. (2020). Stem CellDerived Exosomes Prevent Pyroptosis and Repair Ischemic Muscle Injury through a Novel exosome/circHIPK3/FOXO3a Pathway. Theranostics 10 , 6728-6742. doi:10.7150/thno.42259

Yan, L., and Wu, X. (2020). Exosomes Produced from 3D Cultures of Umbilical Cord Mesenchymal Stem Cells in a Hollow-Fiber Bioreactor Show Improved Osteochondral Regeneration Activity. Cell Biol. Toxicol. 36, 165-178. doi:10.1007/s10565-019-09504-5

Yan, W.-T., Yang, Y.-D., Hu, X.-M., Ning, W.-Y., Liao, L.-S., Lu, S., et al. (2021b). Do pyroptosis, Apoptosis, and Necroptosis (PANoptosis) Exist in Cerebral Ischemia? Evidence from Cell and Rodent Studies. Neural Regen. Res. 17. doi:10.4103/1673-5374.331539

Yan, W. T., Lu, S., Yang, Y. D., Ning, W. Y., Cai, Y., Hu, X. M., et al. (2021a). Research Trends, Hot Spots and Prospects for Necroptosis in the Field of Neuroscience. Neural Regen. Res. 16, 1628-1637. doi:10.4103/16735374.303032

Yang, R., Liu, F., Wang, J., Chen, X., Xie, J., and Xiong, K. (2019). Epidermal Stem Cells in Wound Healing and Their Clinical Applications. Stem Cel. Res. Ther. 10, 229. doi:10.1186/s13287-019-1312-z

Yang, R., Yang, S., Zhao, J., Hu, X., Chen, X., Wang, J., et al. (2020). Progress in Studies of Epidermal Stem Cells and Their Application in Skin Tissue Engineering. Stem Cel. Res. Ther. 11, 303. doi:10.1186/s13287-020-01796-3

Yao, Q., Sun, R., Bao, S., Chen, R., and Kou, L. (2020). Bilirubin Protects Transplanted Islets by Targeting Ferroptosis. Front. Pharmacol. 11, 907. doi:10.3389/fphar.2020.00907

Yin, Y., Chen, F., Li, J., Yang, J., Li, Q., and Jin, P. (2020). AURKA Enhances Autophagy of Adipose Derived Stem Cells to Promote Diabetic Wound Repair via Targeting FOXO3a. J. Invest. Dermatol. 140, 1639-1649. doi:10.1016/ j.jid.2019.12.032

Yoshimatsu, G., Sakata, N., Tsuchiya, H., Minowa, T., Takemura, T., Morita, H., et al. (2015). The Co-transplantation of Bone Marrow Derived Mesenchymal Stem Cells Reduced Inflammation in Intramuscular Islet Transplantation. PLoS One 10, e0117561. doi:10.1371/journal.pone.0117561

Yuan, J., Amin, P., and Ofengeim, D. (2019). Necroptosis and RIPK1-Mediated Neuroinflammation in CNS Diseases. Nat. Rev. Neurosci. 20, 19-33. doi:10.1038/s41583-018-0093-1

Zhang, C., Zhao, C., Chen, X., Tao, R., Wang, S., Meng, G., et al. (2020a). Induction of ASC Pyroptosis Requires Gasdermin D or Caspase-1/11-dependent Mediators and IFN $\beta$ from Pyroptotic Macrophages. Cel Death Dis 11, 470. doi:10.1038/s41419-020-2664-0

Zhang, J., Zhang, J., Zhang, Y., Liu, W., Ni, W., Huang, X., et al. (2020b). Mesenchymal Stem Cells-derived Exosomes Ameliorate Intervertebral Disc Degeneration through Inhibiting Pyroptosis. J. Cel. Mol. Med. 24, 11742-11754. doi:10.1111/jcmm.15784

Zhang, K., Liu, F., Jin, D., Guo, T., Hou, R., Zhang, J., et al. (2019a). Autophagy Preserves the Osteogenic Ability of Periodontal Ligament Stem Cells under High Glucose Conditions in Rats. Arch. Oral Biol. 101, 172-179. doi:10.1016/ j.archoralbio.2019.03.020

Zhang, L., Li, B., Liu, B., and Dong, Z. (2019b). Co-transplantation of Epidermal Neural Crest Stem Cells and Olfactory Ensheathing Cells Repairs Sciatic Nerve Defects in Rats. Front. Cel. Neurosci. 13, 253. doi:10.3389/fncel.2019.00253

Zhang, W., Wang, Y., Kong, J., Dong, M., Duan, H., and Chen, S. (2017). Therapeutic Efficacy of Neural Stem Cells Originating from Umbilical Cord-Derived Mesenchymal Stem Cells in Diabetic Retinopathy. Sci. Rep. 7, 408. doi:10.1038/s41598-017-00298-2

Zhang, Y., Li, R., Rong, W., Han, M., Cui, C., Feng, Z., et al. (2018). Therapeutic Effect of Hepatocyte Growth Factor-Overexpressing Bone Marrow-Derived Mesenchymal Stem Cells on CCl4-Induced Hepatocirrhosis. Cel Death Dis 9, 1186. doi:10.1038/s41419-018-1239-9 
Zhang, Z. N., Chung, S. K., Xu, Z., and Xu, Y. (2014). Oct4 Maintains the Pluripotency of Human Embryonic Stem Cells by Inactivating P53 through Sirt1-Mediated Deacetylation. Stem Cells 32, 157-165. doi:10.1002/stem.1532

Zhang, Z., Yang, M., Wang, Y., Wang, L., Jin, Z., Ding, L., et al. (2016). Autophagy Regulates the Apoptosis of Bone Marrow-Derived Mesenchymal Stem Cells under Hypoxic Condition via AMP-Activated Protein Kinase/mammalian Target of Rapamycin Pathway. Cel Biol. Int. 40, 671-685. doi:10.1002/ cbin. 10604

Zhao, L., Guo, Z., Chen, K., Yang, W., Wan, X., Zeng, P., et al. (2020a). Combined Transplantation of Mesenchymal Stem Cells and Endothelial Colony-Forming Cells Accelerates Refractory Diabetic Foot Ulcer Healing. Stem Cell Int 2020, 8863649. doi:10.1155/2020/8863649

Zhao, L., Hu, C., Zhang, P., Jiang, H., and Chen, J. (2020b). Melatonin Preconditioning Is an Effective Strategy for Mesenchymal Stem Cell-based Therapy for Kidney Disease. J. Cel. Mol. Med. 24, 25-33. doi:10.1111/ jcmm.14769

Zhao, Y., Scott, N. A., Fynch, S., Elkerbout, L., Wong, W. W.-L., Mason, K. D., et al. (2015). Autoreactive T Cells Induce Necrosis and Not BCL-2-Regulated or Death Receptor-Mediated Apoptosis or RIPK3-dependent Necroptosis of
Transplanted Islets in a Mouse Model of Type 1 Diabetes. Diabetologia 58, 140-148. doi:10.1007/s00125-014-3407-5

Conflict of Interest: The authors declare that the research was conducted in the absence of any commercial or financial relationships that could be construed as a potential conflict of interest.

Publisher's Note: All claims expressed in this article are solely those of the authors and do not necessarily represent those of their affiliated organizations, or those of the publisher, the editors and the reviewers. Any product that may be evaluated in this article, or claim that may be made by its manufacturer, is not guaranteed or endorsed by the publisher.

Copyright (c) 2021 Zhang, Wan, Hu, Zhao, Ban, Huang, Yan and Xiong. This is an open-access article distributed under the terms of the Creative Commons Attribution License (CC BY). The use, distribution or reproduction in other forums is permitted, provided the original author(s) and the copyright owner(s) are credited and that the original publication in this journal is cited, in accordance with accepted academic practice. No use, distribution or reproduction is permitted which does not comply with these terms. 